\title{
Helicobacter cynogastricus sp. nov., isolated from the canine gastric mucosa
}

Correspondence

K. Van den Bulck

kvdbulck@prdbe.jnj.com

\author{
K. Van den Bulck, ${ }^{1} \dagger$ A. Decostere, ${ }^{1}$ M. Baele, ${ }^{1}$ P. Vandamme, ${ }^{2}$ J. Mast ${ }^{3}$ \\ R. Ducatelle ${ }^{1}$ and F. Haesebrouck ${ }^{1}$ \\ ${ }^{1}$ Department of Pathology, Bacteriology and Poultry Diseases, Faculty of Veterinary Medicine, \\ Ghent University, Salisburylaan 133, B-9820 Merelbeke, Belgium \\ ${ }^{2}$ Department of Biochemistry, Physiology and Microbiology, Faculty of Sciences, Ghent \\ University, Ledeganckstraat 35, B-9000 Ghent, Belgium \\ ${ }^{3}$ CODA-CERVA-VAR, Groeselenberg 99, B-1180 Brussels, Belgium
}

Helicobacter species are fastidious and slow-growing organisms with specific nutritional and environmental requirements. Three Helicobacter species have previously been cultured from the gastric mucosa of cats and dogs, namely Helicobacter felis, Helicobacter bizzozeronii and Helicobacter salomonis (Hänninen et al., 1996; Jalava et al., 1997; Lee et al., 1988). These three organisms are highly related to each other, both genetically and morphologically, although small morphological differences are perceptible through electron microscopic examination. The thicker and medium-length organism $\mathrm{H}$. felis possesses two or three periplasmic fibrils wrapped around the cell body, while both $H$. bizzozeronii,

tPresent address: Janssen Pharmaceutica N.V., Global Preclinical Development, Turnhoutseweg 30, B-2340 Beerse, Belgium.

The GenBank/EMBL/DDBJ accession number for the 16S rRNA gene sequence of strain $\mathrm{JKM} 4^{\top}$ is DQ004689.

A phylogenetic tree based on 16S rRNA gene sequences for 27 Helicobacter strains and TEM images of strain $\mathrm{JKM} 4^{\top}$ are available as supplementary figures in IJSEM Online. A supplementary table detailing the $16 \mathrm{~S}$ rRNA gene sequence similarity between Helicobacter strains is also available. thinner and longer, and H. salomonis, thick, short and less spiralled, lack such appendages (Utriainen et al., 1997). Recently, an uncultured spiral organism, 'Candidatus Helicobacter heilmannii', was described as occurring in the gastric mucosa of one human and several wild felines (O'Rourke et al., 2004) and it is most probably also present in the gastric mucosa of pet dogs and cats (Van den Bulck et al., 2005a). In addition, less spiralled bacteria with numerous periplasmic fibrils, tentatively named 'Flexispira rappini, have been isolated from the stomachs of various dogs (Hänninen et al., 2003).

A study set up to determine the prevalence of each individual Helicobacter species in the canine and feline stomach led to the isolation of a large spiral organism from the stomach of a dog. In this study, it is suggested that this isolate represents a novel species of the genus Helicobacter.

The strain, designated JKM4 ${ }^{\mathrm{T}}$, was isolated from the antrum region of the stomach of a euthanized dog at the Faculty of Veterinary Medicine, Ghent University, Belgium. Tissue samples were handled as described by Gruntar et al. (2003). Bacteria were grown on brain heart infusion (BHI; Oxoid) 
agar containing $10 \%$ (v/v) horse blood, $5 \mathrm{mg}$ amphotericin $\mathrm{B}^{-1}$ (Fungizone; Bristol-Myers Squibb), Campylobacterselective supplement (Skirrow; Oxoid) (containing $10 \mathrm{mg}$ vancomycin $\mathrm{l}^{-1}, 5 \mathrm{mg}$ trimethoprim lactate $\mathrm{l}^{-1}$ and $2500 \mathrm{U}$ polymyxin $\mathrm{B}^{-1}$ ), Vitox supplement (Oxoid) and Campylobacter growth supplement (MAST; Lucron Bioproducts). Plates were incubated with lids uppermost at $37^{\circ} \mathrm{C}$ under humidified microaerobic conditions in a closed circuit that was created by evacuating $80 \%$ of the normal atmosphere and introducing a gas mixture of $8 \% \mathrm{CO}_{2}, 8 \% \mathrm{H}_{2}$ and $84 \% \mathrm{~N}_{2}$.

Plates were checked every 2 days and BHI broth was added to the agar surface to ensure that the plates did not dry out. Primary growth occurred after 10 days of incubation as an oily aspect on the broth covering the agar medium. Examination of the broth by light microscopy revealed the presence of spiral-shaped, motile cells. Gram-staining revealed that the isolate was Gram-negative and had a helical shape. Growth of subcultures occurred as a spreading layer on moist agar plates. Pinpoint colonies were observed when an abundant amount of bacteria was inoculated onto a dry agar surface; however, bacteria grown on such a medium mostly lost their spiral morphology and transformed to coccoid forms.

Bacteria with typical spiral morphology were harvested in BHI broth and stored at $-70^{\circ} \mathrm{C}$ in a medium consisting of $7 \cdot 5 \mathrm{~g}$ glucose, $25 \mathrm{ml} \mathrm{BHI}$ and $75 \mathrm{ml}$ sterile inactivated horse serum.

Genomic DNA of strain $\mathrm{JKM}_{4}{ }^{\mathrm{T}}$ was extracted using the DNeasy tissue kit (Qiagen) according to the manufacturer's instructions. To determine whether the novel isolate was a member of the genus Helicobacter, a Helicobacter genusspecific PCR was applied, as described previously by Germani et al. (1997). The positive result in this PCR demonstrated that strain $\mathrm{JKM} 4^{\mathrm{T}}$ represents a Helicobacter species.

To identify strain JKM4 ${ }^{\mathrm{T}}$, a multiplex PCR was performed that enables the identification of Helicobacter species previously detected in the gastric mucosa of cats and dogs, namely $H$. felis, H. bizzozeronii and H. salomonis (Jalava et al., 1998; Van den Bulck et al., 2005a). This PCR is based on a part of the tRNA intergenic spacer of Helicobacter species, amplified with TET-labelled primers, and on the urease gene of $H$. felis (NED-labelled primers) and H. bizzozeronii (HEX-labelled primers), as described earlier (Baele et al., 2004). DNA extracted from pure cultures of H. felis, $\mathrm{H}$. salomonis and $H$. bizzozeronii served as positive controls, while highly purified water was included as a negative control. Fluorescently labelled PCR products were separated by means of capillary electrophoresis using an ABI Prism 3100 Genetic Analyzer (Applied Biosystems). Product lengths were determined by interpolation with an internal size standard mixture of GeneScan 500 ROX (Applied Biosystems) and GeneScan 400-HD ROX (Applied Biosystems) using GeneMapper (Applied Biosystems).
Analysis of the PCR products produced from the DNA of strain JKM4 $4^{\mathrm{T}}$ in the multiplex PCR consistently revealed a TET-labelled amplicon of $136 \cdot 6 \mathrm{bp}$, which differed from the TET-labelled amplicons of $H$. felis (137 bp), H. bizzozeronii (136 bp) and $H$. salomonis (134 bp). Additionally, no amplicons were obtained with the NED- or HEX-labelled primers for the urease gene of $\mathrm{H}$. felis or $\mathrm{H}$. bizzozeronii, respectively. These results indicated that strain $\mathrm{JKM} 4^{\mathrm{T}}$ is different from H. salomonis, $H$. felis and H. bizzozeronii.

'Candidatus H. heilmannii' is a hitherto unculturable spiral organism that is highly related phylogenetically to $H$. felis, $H$. salomonis and H. bizzozeronii and may occur in the gastric mucosa of wild carnivores. To exclude the possibility that strain JKM4 ${ }^{\mathrm{T}}$ was identical to 'Candidatus $\mathrm{H}$. heilmannii', DNA of strain JKM4 ${ }^{\mathrm{T}}$ was subjected to a PCR which specifically amplifies a part of the urease gene of this Candidatus organism (O'Rourke et al., 2004). DNA from 'Candidatus $\mathrm{H}$. heilmannii' served as positive control, while highly purified water was included as a negative control. PCR products were separated by gel electrophoresis as described by Baele et al. (2004). PCR products obtained for 'Candidatus H. heilmannii' and strain $\mathrm{JKM}_{4}{ }^{\mathrm{T}}$ were sequenced using the BigDye terminator cycle sequencing kit (Perkin Elmer, Applied Biosystems) on the Genetic Analyzer. The electropherograms were exported and converted to KODON (Applied Maths) and sequences were aligned with GenBank using BLAST.

The 'Candidatus H. heilmannii'-specific PCR resulted in the production of a $320 \mathrm{bp}$ fragment for strain $\mathrm{JKM} 4^{\mathrm{T}}$ which consistently differed from the $380 \mathrm{bp}$ fragment produced from DNA of 'Candidatus H. heilmannii'. Sequence analysis of the $320 \mathrm{bp}$ fragment of strain $\mathrm{JKM} 4^{\mathrm{T}}$ revealed a unique sequence bordered by the primer pair and the sequence obtained was not related to any sequence in GenBank.

The 16S rRNA gene of strain $\mathrm{JKM} 4^{\mathrm{T}}$ was amplified using primers complementary to the conserved edges. Consensus primers $\alpha \beta$-NOT (5'-TCAAACTAGGACCGAGTC) and $\omega \mathrm{MB}$ (5'-TACCTTGTTACTTCACCCCA) were used, as described by Baele et al. (2001). A 1500 bp amplicon amplified in this PCR was sequenced using primers $\mathrm{pD}, \gamma^{\star}, 3$ and $\mathrm{O}^{*}$, as described elsewhere (Coenye et al., 1999). Sequence analysis was performed using the Genetic Analyzer and sequences were aligned with GenBank using BLAST. Phylogenetic analysis was performed using the KODON program. Pairwise alignment similarities were calculated and a dendrogram was constructed using the neighbour-joining method.

The sequence of the $16 \mathrm{~S}$ rRNA gene of strain JKM $4^{\mathrm{T}}$ showed $>97 \%$ similarity to those of $H$. felis, H. bizzozeronii, $H$. salomonis and 'Candidatus $\mathrm{H}$. heilmannii' and the sequence differed by more than $3 \%$ from that of 'Candidatus Helicobacter suis' (see Supplementary Table S1 in IJSEM Online). A phylogenetic tree based on the $16 \mathrm{~S}$ rRNA gene sequences revealed clustering of the novel isolate among Helicobacter species of carnivore origin (see Supplementary Fig. S1 in IJSEM Online). 
Analysis of the urease gene has recently been found to be more discriminatory for species differentiation within gastric Helicobacter species of carnivore origin than $16 \mathrm{~S}$ rRNA gene sequence analysis (O'Rourke et al., 2004). Therefore, a PCR with primers U430f and U1735r was performed to amplify a part of the urease gene, as described previously (O’Rourke et al., 2004).

For H. felis, H. bizzozeronii, H. salomonis and 'Candidatus $\mathrm{H}$. heilmannii', a PCR amplicon of 1224 bp was obtained, while genomic DNA of strain JKM $4^{\mathrm{T}}$ produced a series of aspecific fragments instead of the expected $1224 \mathrm{bp}$ fragment. The result confirms that strain $\mathrm{JKM} 4^{\mathrm{T}}$ is different from H. felis, H. salomonis, H. bizzozeronii and 'Candidatus $\mathrm{H}$. heilmannii'.

PAGE of whole-cell proteins of strain JKM $4^{\mathrm{T}}$ was performed in order to establish its relationship with other cultured Helicobacter species. For this purpose, strain $\mathrm{JKM} 4^{\mathrm{T}}$ was grown on Mueller-Hinton agar supplemented with $5 \%$ $(\mathrm{v} / \mathrm{v})$ horse blood and incubated at $37^{\circ} \mathrm{C}$ in a microaerobic atmosphere as described above. A whole-cell protein extract was prepared and SDS-PAGE was performed as described previously (Pot et al., 1994). Whole-cell protein profiles of reference strains of $H$. bizzozeronii, $H$. salomonis and $H$. felis and of type and reference strains of other Helicobacter species were available from previous studies (Jalava et al., 1998, 2001). Densitometric analysis, normalization and interpolation of the protein profiles and numerical analysis were performed using the GelCompar software package version 4.2 (Applied Maths). The similarity between all pairs of traces was expressed by the Pearson product-moment correlation coefficient, presented as percentages of similarity.

The whole-cell protein profile of strain $\mathrm{JKM} 4^{\mathrm{T}}$ differed considerably from those of the reference strains of other
Helicobacter species. Correlation levels to the protein profiles of other Helicobacter reference strains were all below $80 \%$. Therefore, we conclude that strain $\mathrm{JKM} 4^{\mathrm{T}}$ represents a novel Helicobacter species. Whole-cell protein electrophoresis is a taxonomic tool that generally allows closely related species to be distinguished (Vandamme et al., 1996). For many Campylobacter and Helicobacter species, the correlation between whole-cell protein pattern similarity and the level of DNA-DNA hybridization has been documented (Costas et al., 1990; Jalava et al., 1998, 2001; On et al., 1995; Vandamme et al., 1989, 1990, 1991, 1992a, b, 1997, 2000), even for species such as Helicobacter cinaedi and Campylobacter hyointestinalis, where substantial 16S rRNA gene sequence diversity has been observed (Vandamme et al., 2000). The correlation between protein pattern similarity and the level of DNA-DNA hybridization has also been demonstrated for the phylogenetic cluster comprising $H$. bizzozeronii, $H$. felis and H. salomonis (Jalava et al., 1998, 2001). Whole-cell protein electrophoresis has therefore been recommended as an alternative method for taxonomic discrimination at the species level in the recommended minimal standards for describing novel Helicobacter species (Dewhirst et al., 2000). The result of the numerical analysis of the protein profiles of strain $\mathrm{JKM} 4^{\mathrm{T}}$ and its nearest cultured phylogenetic neighbours $H$. bizzozeronii, $H$. salomonis and $H$. felis is shown in Fig. 1.

The morphology of strain JKM4 ${ }^{\mathrm{T}}$ was studied by means of scanning and transmission electron microscopy (SEM, TEM). For these examinations, bacterial cultures were negatively stained (Houf et al., 2005) or they were fixed in $2.5 \%$ glutaraldehyde and $2 \%$ paraformaldehyde in cacodylate buffer $(0 \cdot 1 \mathrm{M}, \mathrm{pH} 7 \cdot 3)$. They were post-fixed in $1 \%$ $(\mathrm{w} / \mathrm{v})$ osmium tetroxide in distilled water. Samples for SEM were dehydrated in alcohol and acetone for subsequent
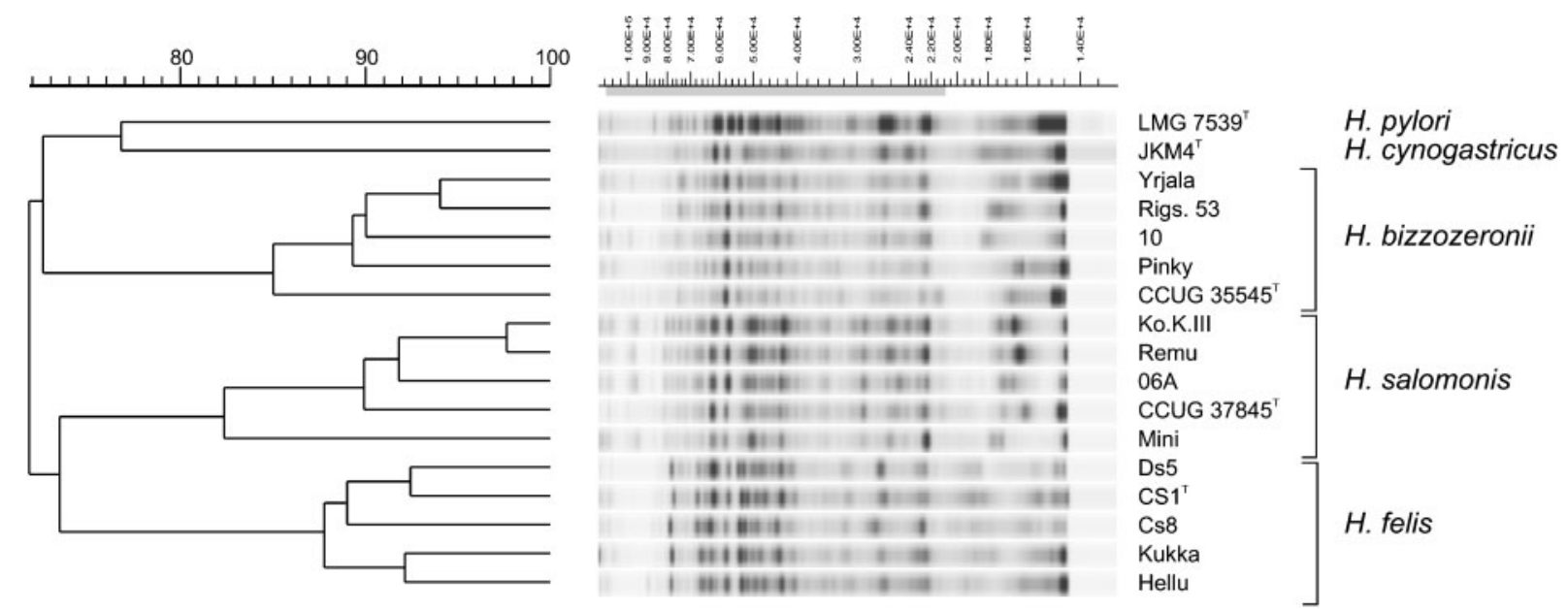

Fig. 1. Dendrogram derived from the numerical analysis of the whole-cell protein profiles of strain JKM4 ${ }^{\top}, H$. pylori, $H$. acinonychis, Helicobacter mustelae, Helicobacter aurati, Helicobacter muridarum, H. canis, H. bizzozeronii, H. salomonis and $H$. felis reference strains. The grey bar in the marker lane indicates the part of the protein profile that was used in the numerical analysis. 
critical-point drying in liquid $\mathrm{CO}_{2}$, glued with carbon cement on to aluminium stubs, sputtered with a gold layer and examined with a Philips 501 SEM. Samples for TEM were block-stained with $2 \%(\mathrm{w} / \mathrm{v})$ uranyl acetate in distilled water and dehydrated in ethanol. They were embedded in Epon-Spurr's $(1: 1)$ medium. Ultrathin sections were cut from samples in which bacteria were demonstrated, stained with lead citrate and examined with a Philips EM $208 S$.

Cells of strain JKM $4^{\mathrm{T}}$ were large spiral cells, $10-18 \mu \mathrm{m}$ long and approximately $1 \mu \mathrm{m}$ wide, with three to eight spirals per cell (see Supplementary Fig. S2 in IJSEM Online). The presence of sheathed flagella located slightly off-centre at both ends of the cells demonstrated the morphological resemblance of strain JKM4 ${ }^{\mathrm{T}}$ to $H$. salomonis, H. bizzozeronii and $H$. felis (Utriainen et al., 1997). The flagella of strain $\mathrm{JKM} 4^{\mathrm{T}}$ were blunt-ended and the terminal diameter was wider than the mean diameter of the flagellar body. Whereas periplasmic fibrils are thought to be a characteristic feature of H. felis (Utriainen et al., 1997), a periplasmic fibril running along the external side of the helix was detected on every cell of strain $\mathrm{JKM} 4^{\mathrm{T}}$. Coccoid forms were observed in cultures older than 4 days, as are also found in older cultures of $H$. salomonis, $H$. bizzozeronii and $H$. felis. Ultrastructural characteristics were examined several times after several subcultures and were the same in all studies.

Biochemical and tolerance tests were carried out as recommended by Dewhirst et al. (2000). The novel isolate was tested for oxidase, catalase (with $3 \%$ hydrogen peroxide) and rapid urease activities and for hydrolysis of indoxyl acetate. The strain was also subjected to API Campy test strips (bioMérieux), which include tests for urease activity, nitrate reductase activity, esterase activity, hippurate hydrolysis, $\gamma$-glutamyl transpeptidase activity, alkaline phosphatase activity, triphenyltetrazolium chloride (TTC) reduction, pyrrolidonyl arylamidase and L-arginine and L-aspartate arylamidase activities. Tolerance of $1 \%$ glycine (Merck) and $1.5 \% \mathrm{NaCl}$ (Merck) was tested on tryptic blood agar base (Oxoid) supplemented with $10 \%$ horse blood, as recommended by the Cape Town protocol for Campylobacteriaceae and helicobacters. Tolerance of ox bile was tested by plating the bacteria on unsalted MacConkey agar (Oxoid). Growth was tested on BHI blood agar, Brucella blood agar (Oxoid) and Mueller-Hinton blood agar. Growth at 25, 30, 37 and $42^{\circ} \mathrm{C}$ was determined on BHI blood agar. All media were incubated for 7 days in a microaerobic atmosphere at $37^{\circ} \mathrm{C}$. In addition, growth on blood-supplemented BHI agar was tested in aerobic, aerobic with $5 \% \mathrm{CO}_{2}$, microaerobic and anaerobic atmospheres.

The salient tests that distinguish the novel isolate from other gastric helicobacters and from H. canis are listed in Table 1, while the other biochemical and growth characteristics are given in the description below.

Susceptibility to metronidazole, ampicillin, clarithromycin, tetracycline, enrofloxacin, lincomycin, tylosin, neomycin, spectinomycin and gentamicin was tested on MuellerHinton agar (Oxoid) supplemented with $10 \%$ horse blood using the agar dilution method as previously described (Van den Bulck et al., 2005b). All antimicrobials were supplied by Sigma as standard powders with known potencies, except for enrofloxacin which was purchased from Bayer. These tolerance test preparations were incubated for 7 days in a microaerobic atmosphere at $37^{\circ} \mathrm{C}$. The novel isolate was susceptible to all antimicrobials tested, as indicated by low MIC values, ranging from $0 \cdot 03$ to $0 \cdot 25 \mu \mathrm{g} \mathrm{ml}^{-1}$.

Although until now only $H$. felis, $H$. bizzozeronii and $H$. salomonis have been isolated from the gastric mucosa of dogs, evidence has been presented previously that indicates that a significant proportion of the spiral organisms in the canine and feline stomach is unculturable (Cattoli et al.,

Table 1. Differential characteristics of $H$. cynogastricus $\mathrm{JKM} 4^{\top}$ sp. nov. and other Helicobacter species

Species: 1, H. cynogastricus sp. nov. (data from this study); 2, H. felis (Jalava et al., 1997); 3, H. bizzozeronii (Jalava et al., 1997); 4, H. salomonis (Jalava et al., 1997); 5, H. pylori (Jalava et al., 1997); 6, H. acinonychis (Eaton et al., 1993); 7, H. aurati (Patterson et al., 2000); 8, H. muridarum (Lee et al., 1992); 9, H. mustelae (Fox et al., 1988); 10, H. canis (Stanley et al., 1993). +, Positive; -, negative.

\begin{tabular}{|c|c|c|c|c|c|c|c|c|c|c|}
\hline Characteristic & 1 & 2 & 3 & 4 & 5 & 6 & 7 & 8 & 9 & 10 \\
\hline Cell length $(\mu \mathrm{m})$ & $10-18$ & $5-7 \cdot 5$ & 5-10 & $5-7$ & $2 \cdot 5-5$ & $1 \cdot 2-2$ & $4-8$ & $3 \cdot 5-5$ & 2 & $3-4$ \\
\hline Cell width $(\mu \mathrm{m})$ & $0 \cdot 8-1 \cdot 0$ & $0 \cdot 4$ & $0 \cdot 3$ & $0 \cdot 8-1 \cdot 2$ & $0 \cdot 5-1 \cdot 0$ & $0 \cdot 3$ & $0 \cdot 6$ & $0 \cdot 5-0 \cdot 6$ & $0 \cdot 5$ & $0 \cdot 25-0 \cdot 5$ \\
\hline Periplasmic fibrils & + & + & - & - & - & - & + & + & - & - \\
\hline Location of flagella & Bipolar & Bipolar & Bipolar & Bipolar & Polar & Polar & Bipolar & Bipolar & Lateral polar & Bipolar \\
\hline No. of flagella & $6-12$ & $14-20$ & $10-20$ & $10-23$ & $4-8$ & $2-5$ & $7-10$ & $10-14$ & $10-15$ & 2 \\
\hline Catalase & + & + & + & + & + & + & + & + & + & - \\
\hline Urease & + & + & + & + & + & + & + & + & + & - \\
\hline Nitrate reduction & + & + & + & + & - & - & - & - & + & - \\
\hline Indoxyl acetate hydrolysis & - & - & + & + & - & + & + & + & + & + \\
\hline Alkaline phosphatase & + & + & + & + & + & + & - & + & + & + \\
\hline Growth at $42^{\circ} \mathrm{C}$ & - & - & + & - & - & + & + & - & + & + \\
\hline
\end{tabular}


1999; Jalava et al., 1998). The present study demonstrates the existence of a fourth cultured Helicobacter species able to colonize the canine stomach, for which we propose the name Helicobacter cynogastricus sp. nov.

Following discussions held at the meetings of the International Committee on Systematics of Prokaryotes (ICSP) and its Judicial Commission (JC) in San Francisco in 2005, and in anticipation of the published minutes of the JC and ICSP, a committee consisting of the Chairman of the ICSP, the Chairman of the JC of the ICSP and the Editor of the International Journal of Systematic and Evolutionary Microbiology has granted an exception in this instance to Rule 27(3) of the Bacteriological Code governing the deposit of type material in two different collections in two different countries. Helicobacter cynogastricus sp. nov. $\mathrm{JKM}^{\mathrm{T}}$ has been submitted to the CCUG and NCTC culture collections but, due to the extremely fastidious nature of Helicobacter species, the strain has not been able to be revived or stored after lyophilisation. Attempts are still underway to complete the deposition of the type strain in a second culture collection.

\section{Description of Helicobacter cynogastricus sp. nov.}

Helicobacter cynogastricus (cy.no.gas'tri.cus. N.L. gen. n. cyno dog, from Gr. n. kyon kyno dog; N.L. masc. adj. gastricus of the stomach, from Gr. n. gaster stomach; cynogastricus N.L. masc. adj. of a dog's stomach).

Cells are tightly coiled spirals that are up to $1 \mu \mathrm{m}$ wide by $10-18 \mu \mathrm{m}$ long. They possess one periplasmic fibril running along the external side of the helix. In older cultures, coccoid cells predominate. Cells are Gram-negative and nonsporulating. They are motile by means of tufts of $6-12$ sheathed flagella at one or both ends of the cell with a movement similar to that of $H$. felis and $H$. bizzozeronii. Growth on moist agar plates occurs as a spreading film or as an oily layer on biphasic culture media in a microaerobic and anaerobic atmosphere. Pinpoint colonies may be formed on dry agar plates, although bacteria are transformed into coccoids. Grows at 30 and $37^{\circ} \mathrm{C}$, but not at 25 or $42^{\circ} \mathrm{C}$. Does not grow on media containing $1 \%$ ox bile, $1 \%$ glycine or $1.5 \% \mathrm{NaCl}$. Oxidase-, catalase- and urease-positive. Reduces nitrate and TTC and tests positive for esterase, $\gamma$-glutamyl transpeptidase, L-arginine arylamidase and alkaline phosphatase. Negative results are obtained in tests for hippurate and indoxyl acetate hydrolysis and for pyrrolidonyl arylamidase and L-aspartate arylamidase activities. The clinical significance of $H$. cynogastricus is unknown.

The type strain, JKM4 ${ }^{\mathrm{T}}\left(=\mathrm{LMG} 23188^{\mathrm{T}}\right.$ ), was isolated from the gastric mucosa of a dog.

\section{Acknowledgements}

This work was supported by the Research Fund of Ghent University, Belgium, Code GOA12050602. The authors are very grateful to Jurgen De Craene for his excellent technical assistance and to Dr Jani
O'Rourke for providing DNA of 'Candidatus H. heilmannii' as a positive control in PCR tests. We also thank Stefanie Van Trappen and Emly Samyn for preparing the protein extracts.

\section{References}

Baele, M., Devriese, L. A. \& Haesebrouck, F. (2001). Lactobacillus agilis is an important component of the pigeon crop flora. J Appl Microbiol 91, 488-491.

Baele, M., Van den Bulck, K., Decostere, A., Vandamme, P., Hänninen, M. L., Ducatelle, R. \& Haesebrouck, F. (2004). Multiplex PCR assay for differentiation of Helicobacter felis, H. bizzozeronii and H. salomonis. J Clin Microbiol 42, 1115-1122.

Cattoli, G., Van Vugt, R., Zanoni, R. G., Sanguinetti, V., Chiocchetti, R., Gualtieri, M., Vandenbroucke-Grauls, C. M., Gaastra, W. \& Kusters, J. G. (1999). Occurrence and characterization of gastric Helicobacter spp. in naturally infected dogs. Vet Microbiol 70, 239-250.

Coenye, T., Falsen, E., Vancanneyt, M., Hoste, B., Govan, J. R. W., Kersters, K. \& Vandamme, P. (1999). Classification of Alcaligenes faecalis-like isolates from the environment and human clinical samples as Ralstonia gilardii sp. nov. Int J Syst Bacteriol 49, 405-413.

Costas, M., Pot, B., Vandamme, P., Kersters, K., Owen, R. J. \& Hill, L. R. (1990). Interlaboratory comparative study of the numerical analysis of one-dimensional sodium dodecyl sulphate-polyacrylamide gel electrophoretic protein patterns of Campylobacter strains. Electrophoresis 11, 467-474.

Dewhirst, F. E., Fox, J. G. \& On, S. L. (2000). Recommended minimal standards for describing new species of the genus Helicobacter. Int J Syst Evol Microbiol 50, 2231-2237.

Eaton, K. A., Dewhirst, F. E., Radin, M. J., Fox, J. G., Paster, B. J., Krakowka, S. \& Morgan, D. R. (1993). Helicobacter acinonyx sp. nov., isolated from cheetahs with gastritis. Int J Syst Bacteriol 43, 99-106.

Fox, J. G., Taylor, N. S., Edmonds, P. \& Brenner, D. J. (1988). Campylobacter pylori subsp. mustelae subsp. nov., isolated from the gastric mucosa of ferrets (Mustela putorius furo), and an emended description of Campylobacter pylori. Int J Syst Bacteriol 38, 367-370.

Germani, Y., Dauga, C., Duval, P., Huerre, M., Levy, M., Pialoux, G., Sansonetti, P. \& Grimont, P. A. (1997). Strategy for the detection of Helicobacter species by amplification of 16S rRNA genes and identification of $\mathrm{H}$. felis in a human gastric biopsy. Res Microbiol 148, 315-326.

Gruntar, I., Mehle, J., Krt, B., Ocepek, M., Gombac, M., Cerne, M. \& Pogacnik, M. (2003). New approaches in isolation of Helicobacter spp. from gastric mucosa in dogs. Int J Med Microbiol 293 (Supplement), 65.

Hänninen, M. L., Happonen, I., Saari, S. \& Jalava, K. (1996). Culture and characteristics of Helicobacter bizzozeronii, a new canine gastric Helicobacter sp. Int J Syst Bacteriol 46, 160-166.

Hänninen, M. L., Utriainen, M., Happonen, I. \& Dewhirst, F. E. (2003). Helicobacter sp. flexispira $16 \mathrm{~S}$ rDNA taxa 1, 4 and 5 and Finnish porcine Helicobacter isolates are members of the species Helicobacter trogontum (taxon 6). Int J Syst Evol Microbiol 53, 425-433.

Houf, K., On, S. L. W., Coenye, T., Mast, J., Van Hoof, J. \& Vandamme, P. (2005). Arcobacter cibarius sp. nov., isolated from broiler carcasses. Int J Syst Evol Microbiol 55, 713-717.

Jalava, K., Kaartinen, M., Utriainen, M., Happonen, I. \& Hänninen, M. L. (1997). Helicobacter salomonis sp. nov., a canine gastric Helicobacter sp. related to Helicobacter felis and Helicobacter bizzozeronii. Int J Syst Bacteriol 47, 975-982. 
Jalava, K., On, S. L., Vandamme, P. A., Happonen, I., Sukura, A. \& Hänninen, M. L. (1998). Isolation and identification of Helicobacter spp. from canine and feline gastric mucosa. Appl Environ Microbiol 64, 3998-4006.

Jalava, K., On, S. L., Harrington, C. S., Andersen, L. P., Hänninen, M. L. \& Vandamme, P. A. (2001). A cultured strain of "Helicobacter heilmannii", a human gastric pathogen, identified as $H$. bizzozeronii: evidence for zoonotic potential of Helicobacter. Emerg Infect Dis 7, 1036-1038.

Lee, A., Hazell, S. L., O'Rourke, J. \& Kouprach, S. (1988). Isolation of a spiral-shaped bacterium from the cat stomach. Infect Immun 56, 2843-2850.

Lee, A., Phillips, M. W., O'Rourke, J. L. \& 8 other authors (1992). Helicobacter muridarum sp. nov., a microaerophilic helical bacterium with a novel ultrastructure isolated from the intestinal mucosa of rodents. Int J Syst Bacteriol 42, 27-36.

On, S. L. W., Bloch, B., Holmes, B., Hoste, B. \& Vandamme, P. (1995). Campylobacter hyointestinalis subsp. lawsonii subsp. nov., isolated from the porcine stomach, and an emended description of Campylobacter hyointestinalis. Int J Syst Bacteriol 45, 767-774.

O’Rourke, J. L., Solnick, J. V., Neilan, B. A., Seidel, K., Hayter, R., Hansen, L. M. \& Lee, A. (2004). Description of 'Candidatus Helicobacter heilmannii' based on DNA sequence analysis of $16 \mathrm{~S}$ rRNA and urease genes. Int J Syst Evol Microbiol 54, 2203-2211.

Patterson, M. M., Schrenzel, M. D., Feng, Y., Xu, S., Dewhirst, F. E., Paster, B. J., Thibodeau, S. A., Versalovic, J. \& Fox, J. G. (2000). Helicobacter aurati sp. nov., a urease-positive Helicobacter species cultured from gastrointestinal tissues of Syrian hamsters. J Clin Microbiol 38, 3722-3728.

Pot, B., Devriese, L. A., Hommez, J., Miry, C., Vandemeulebroecke, K., Kersters, K. \& Haesebrouck, F. (1994). Characterization and identification of Vagococcus fluvialis strains isolated from domestic animals. J Appl Bacteriol 77, 362-369.

Stanley, J., Linton, D., Burnens, A. P., Dewhirst, F. E., Owen, R. J., Porter, A., On, S. L. \& Costas, M. (1993). Helicobacter canis sp. nov., a new species from dogs: an integrated study of phenotype and genotype. J Gen Microbiol 139, 2495-2504.

Utriainen, M., Jalava, K., Sukura, A. \& Hanninen, M. L. (1997). Morphological diversity of cultured canine gastric Helicobacter spp. Comp Immunol Microbiol Infect Dis 20, 285-297.
Vandamme, P., Falsen, E., Pot, B., Hoste, B., Kersters, K. \& De Ley, J. (1989). Identification of EF group 22 campylobacters from gastroenteritis cases as Campylobacter concisus. J Clin Microbiol 27, 1775-1781.

Vandamme, P., Pot, B., Falsen, E., Kersters, K. \& De Ley, J. (1990). Intra- and interspecific relationships of veterinary campylobacters revealed by numerical analysis of electrophoretic protein profiles and DNA:DNA hybridizations. Syst Appl Microbiol 13, 295-303.

Vandamme, P., Pot, B. \& Kersters, K. (1991). Differentiation of campylobacters and Campylobacter-like organisms by numerical analysis of one-dimensional electrophoretic protein patterns. Syst Appl Microbiol 14, 57-66.

Vandamme, P., Dewettinck, D. \& Kersters, K. (1992a). Application of numerical analysis of electrophoretic protein profiles for the identification of thermophilic campylobacters. Syst Appl Microbiol 15, 402-408.

Vandamme, P., Vancanneyt, M., Pot, B. \& 10 other authors (1992b). Polyphasic taxonomic study of the emended genus Arcobacter with Arcobacter butzleri comb. nov. and Arcobacter skirrowii sp. nov., an aerotolerant bacterium isolated from veterinary specimens. Int J Syst Bacteriol 42, 344-356.

Vandamme, P., Pot, B., Gillis, M., De Vos, P., Kersters, K. \& Swings, J. (1996). Polyphasic taxonomy, a consensus approach to bacterial systematics. Microb Rev 60, 407-438.

Vandamme, P., van Doorn, L.-J., Al Rashid, S. T., Quint, W. G. V., van der Plas, J., Chan, V. L. \& On, S. L. W. (1997). Campylobacter hyoile Alderton et al. 1995 and Campylobacter coli Véron and Chatelain 1973 are subjective synonyms. Int J Syst Bacteriol 47, 1055-1060.

Vandamme, P., Harrington, C. S., Jalava, K. \& On, S. L. (2000). Misidentifying helicobacters: the Helicobacter cinaedi example. J Clin Microbiol 38, 2261-2266.

Van den Bulck, K., Decostere, A., Baele, M., Driessen, A., Debongnie, J. C., Burette, A., Stolte, M., Ducatelle, R. \& Haesebrouck, F. (2005a). Identification of non-Helicobacter pylori spiral organisms in gastric samples from humans, dogs and cats. J Clin Microbiol 43, 2256-2260.

Van den Bulck, K., Decostere, A., Gruntar, I., Baele, M., Krt, B., Ducatelle, R. \& Haesebrouck, F. (2005b). In vitro antimicrobial susceptibility testing of Helicobacter felis, $H$. bizzozeronii and $H$. salomonis. Antimicrob Agents Chemother 49, 2997-3000. 